\title{
Method for optimizing the protecting pillars parameters in underground coal mining
}

\author{
Volodymyr Bondarenko ${ }^{1}$, Iryna Kovalevska ${ }^{1, *}$, Hennadii Symanovych ${ }^{2}$, Serhii Poimanov ${ }^{1}$, and Viktor Pochepov ${ }^{1}$ \\ ${ }^{1}$ Dnipro University of Technology, Department of Mining Engineering and Education, Dnipro, 49005, Ukraine \\ ${ }^{2}$ Dnipro University of Technology, Department of Labour Protection and Civil Safety, Dnipro, 49005, Ukraine
}

\begin{abstract}
A method for optimizing the protecting pillars parameters during the study of soft enclosing rocks (in Ukraine mines) is represented. The necessity of a differentiated approach has been substantiated when choosing the protecting pillar parameters based on the geomechanical factors analysis influencing the state of massif. Mining and geological situation was analysed. It has been studied a stress-strain state (SSS) along the protecting pillar width with account of the mined-out space on the basis of a computational experiment and is presented in the form of curves of vertical and horizontal stresses distribution, as well as stresses intensity distribution. The recommended engineering decisions have been substantiated and the SSS of fastening and security structures has been analysed. A certain reserve of the fastening structure loadbearing capacity as part of the frame support and the combined roof-bolting system has been revealed. An evidence base has been created for the measures development on conducting and maintaining mine workings in the zone of the stope works influence. The recommendations have been developed on the protecting pillar formation with a width of at least $40-45 \mathrm{~m}$ to exclude the stope works influence.
\end{abstract}

\section{Introduction}

At present, there are trends to drive out the hydrocarbons from use in the energy sector. But, according to longterm predictions, the volumes of coal output will grow to 2040 by $20 \%$ from 7.7 to 9.23 bill t. The data presented in the work [1], show the presence of a positive attitude to the coal industry development in Ukraine. Coal is the only energy raw material, the reserves of which are potentially enough to ensure the energy security of our state and promote the development of the metallurgical and chemical industries. If in the structure of world reserves of the organic fuel main types, coal is $67 \%$, then in Ukraine - $95.45 \%$ [2].

The necessity to introduce innovative coal technologies into production has a political, social-andecological, as well as economic basis.

One of the resource-saving trends in extraction of mineral resources is the optimization of the protecting pillars parameters, in which up to $70 \%$ of standard quality coal reserves are concentrated in exploited fields. This problem is complex to solve at the Western Donbas mines that is explained by specific mining and geological conditions [3, 4]. Coal in this region is hard enough (hardness coefficient according to M. M. Protodiakonov $f=2.0-3.5$ ), and the enclosing rocks - argillites, siltstones and sandstones are weakly stable $(f=0.8-2.5)$. Therefore, when conducting the work, decisions were made to leave the pillars with large width [5].

The operational state of mine workings depends on measures aimed to protect them from the rock pressure manifestations, which are provided for at all stages of the mine working existence: design, construction, operation, and abandonment $[6,7]$. Unfortunately, the planned and implemented measures sometimes do not make possible to maintain a stable state of mine working $[8,9]$. On the other hand, the experience of coal mining enterprises exploitation indicates the situations arising where, according to well-founded design decisions, the stability of mine workings is excessive and is ensured by the unnecessary waste of resources, primarily mineral resources, for example, within natural protecting objects, the so-called pillars. Such pillars enable to protect mine workings, and the mineral resources loss within the entire mine reaches $10 \%$ or more of the mine's total reserves. That is why, determining the geometric pillars dimensions is an important and urgent task, the solution to which will reduce losses, increase output and optimize the coal product costs $[10,11]$.

The group of pillars is of particular interest, designed to ensure the stability of inclined overburden workings. This group includes, first of all, slopes and gravity inclines, of which should be 3 , when uncovering the panel: slope (gravity incline) and two passage ways, between which there are pillars preventing the mutual influence of these mine workings. In addition, there are also pillars, the purpose of which is to protect the complex of mine workings from the bearing pressure influence at the front of the stope works. The width of such pillars with increasing depth of mining reaches $150-200 \mathrm{~m}$ [12], which, of course, leads to significant

* Corresponding author: kovalevska_i@yahoo.com 
losses of coal reserves prepared actually for mining.

Thus, the development of a methodology for a possible reduction in the protecting pillars width is an urgent applied research task, which is important for the mining industry. The second solution component to this problem is the substantiation of resource-saving technologies for fastening and maintaining mine workings in the zone of the stope works influence.

\section{Research methodology, analysis of mining-geological and mining- engineering conditions}

The problem of optimizing the protecting pillar width was solved using the example of "Dniprovska" Mine of Dniprovska Mine Group, DTEK "Pavlohradvuhillia", PRAT. The plans for mining operations development along the seam $C_{10}{ }^{l}$ in "Dniprovska" Mine provide for the further development of the North Drain Slope (NDS) to the width of two extraction sites: the 1100 longwall face will be mined-out in 2020 , the extraction of reserves at the 1001 longwall face will be completed in 2021. To ensure the two indicated mining sites operation, in 2019 it is planned to develop the NDS to the area of entry to the 1100 prefabricated drift, and in 2020 - until junction with the 1101 prefabricated drift.

The NDS protection from the stope works influence in the 1100 and 1001 longwall faces is provided by trapezium-shaped coal pillars, in which the minimum distance $L_{p r}$ from the face entry to the NDS is $85-90 \mathrm{~m}$. According to the normative documents on the mine workings location, such a width of the protecting pillar should be sufficient to maintain the NDS of the seam $C_{10}{ }^{l}$ in a satisfactory state for the entire period of its exploitation. On the other hand, the experience of mining operations in the Western Donbas indicates the ambiguity of the link between the protecting pillar width and stability degree of the main preparatory mine workings [13]: their state is enough satisfactory (in accord with safety standards and rules) with a protecting pillar width of several tens of meters. On the contrary, the case when they are protected by a coal pillar with a width of about $200 \mathrm{~m}$ and sometimes even more does not meet the requirements for safe operation. Obviously, a differentiated approach is required when choosing the protecting pillar width, based on the analysis of geomechanical factors influencing the massif state in the location area of a newly constructed NDS site of the seam $C_{10}$. Thus, the task of research is to study the possibility of reducing the protecting pillar width along with the measures development on conducting and maintaining the NDS of the seam $C_{10}$, taking into account the influence of the rock pressure anomalies during mining of the 1100 and 1001 longwall faces.

In accordance with the plan of mining operations development (Figure 1), at this mine field site, the depth of placement of the constructed NDS site of the seam $C_{10}{ }^{l}$ is $H=420-450 \mathrm{~m}$, and tectonic disturbances can occur along the trace of mine working. According to Geological Survey data of "Dniprovska" Mine, complex mining-geological and hydrogeological conditions are expected when developing the NDS of the seam $C_{10}{ }^{l}$, which are conditioned by several factors. Firstly, mine working crosses two dangerous areas.

Secondly, the immediate bottom rocks of the coal seam $C_{10}{ }^{l}$ represented by siltstone, are characterized by low strength characteristics, and when being moistened, they are prone to soaking and heaving [14].

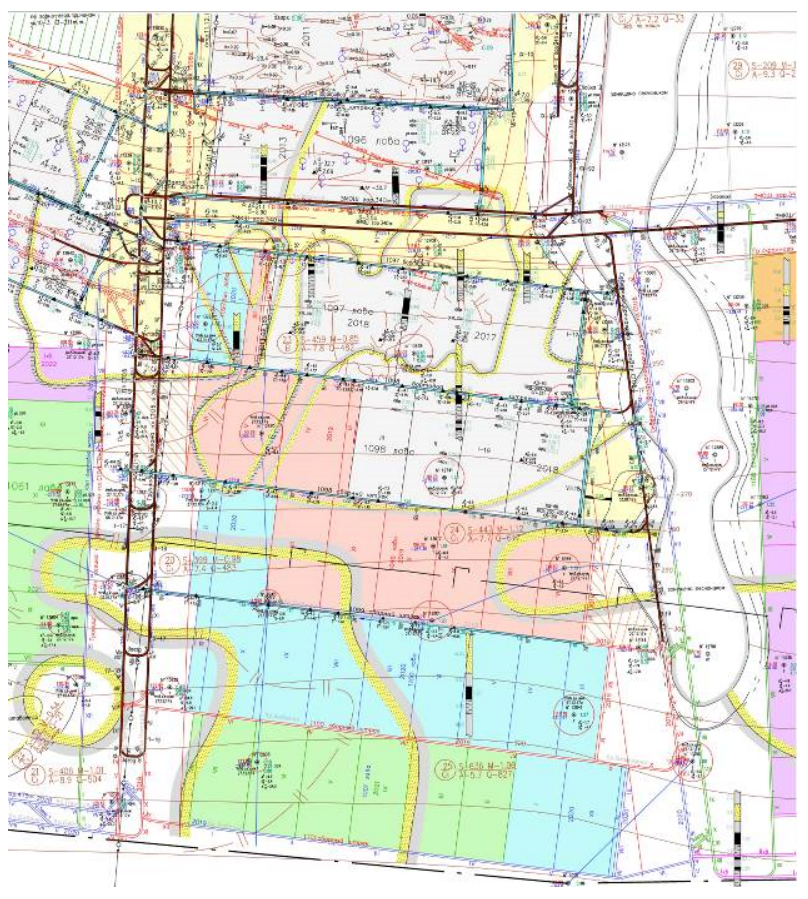

Fig. 1. Excerption from the plan of mining operations along the seam $C_{10}{ }^{l}$ of "Dniprovska" Mine along the NDS trace in the area of the planned 1100 and 1001 longwall faces.

Thirdly, the water-cut of mine working is conditioned by the sandstone occurring in the main roof and coal seams $C_{10}{ }^{l}$ and $C_{10}{ }^{u}$, as well as the possible water ingress in the crossover point of the tectonic disturbances of "fault" pattern [15]. The expected water inflow in the face space is $1.5-6.0 \mathrm{~m}^{3} / \mathrm{h}$, and with long stops, an increase is possible of up to $10 \mathrm{~m}^{3} / \mathrm{h}$. Furthermore, an additional water inflow will be formed from the 1097 prefabricated drift, 1097 boundary drift, 1098 prefabricated and 1099 prefabricated drifts, which in total will increase water inflow through the NDS of the seam $C_{10}{ }^{l}$ up to $25 \mathrm{~m}^{3} / \mathrm{h}$.

The North Drain Slope of the seam $C_{10}{ }^{l}$ will be developed along the coal seams $C_{10}{ }^{l}$ and $C_{10}{ }^{u}$, as well as along the rocks of their roof and bottom, represented by argillite, siltstone and sandstone, which occur at an angle of $3-6^{\circ}$ in the north-east direction.

The stability of the enclosing massif and the preliminary prediction of rock pressure manifestations were assessed based on the geological sheet along the NDS of the seam $C_{10}^{l} 265 \mathrm{~m}$ horizon (Figure 2).

The coal-bearing stratum geology at the newly constructed NDS site of the seam $C_{10}{ }^{l}$ has been studied in two directions:

- the area of the bearing pressure propagation in the protecting pillar during mining out the 1100 and 1001 longwall faces;

- assumed rock pressure manifestations around and 
on the SDS contour to substantiate its fastening scheme.

At the first site of the mine working length, the following peculiarities of the coal-bearing stratum state are predicted.

The immediate roof of the seam $C_{10}$, represented by argillite with a thickness of $1.2 \mathrm{~m}$, is characterized by an increased tendency to cleavage and collapse, despite the mean lithotype hardness (uniaxial compression resistance in the sample $\sigma_{\text {compr }}=20.6-21.5 \mathrm{MPa}$ ). The unstable state of immediate roof (when it is outcropped) is determined by two reasons. The first reason is a very low argillite adhesion to the coal seam $C_{10}{ }^{l}$ and the overlying sandstone. The second reason is that both of these lithotypes are water-flooded and the small argillite thickness causes its intense water saturation throughout the entire volume with a loss of hardness at least twice according to [16].

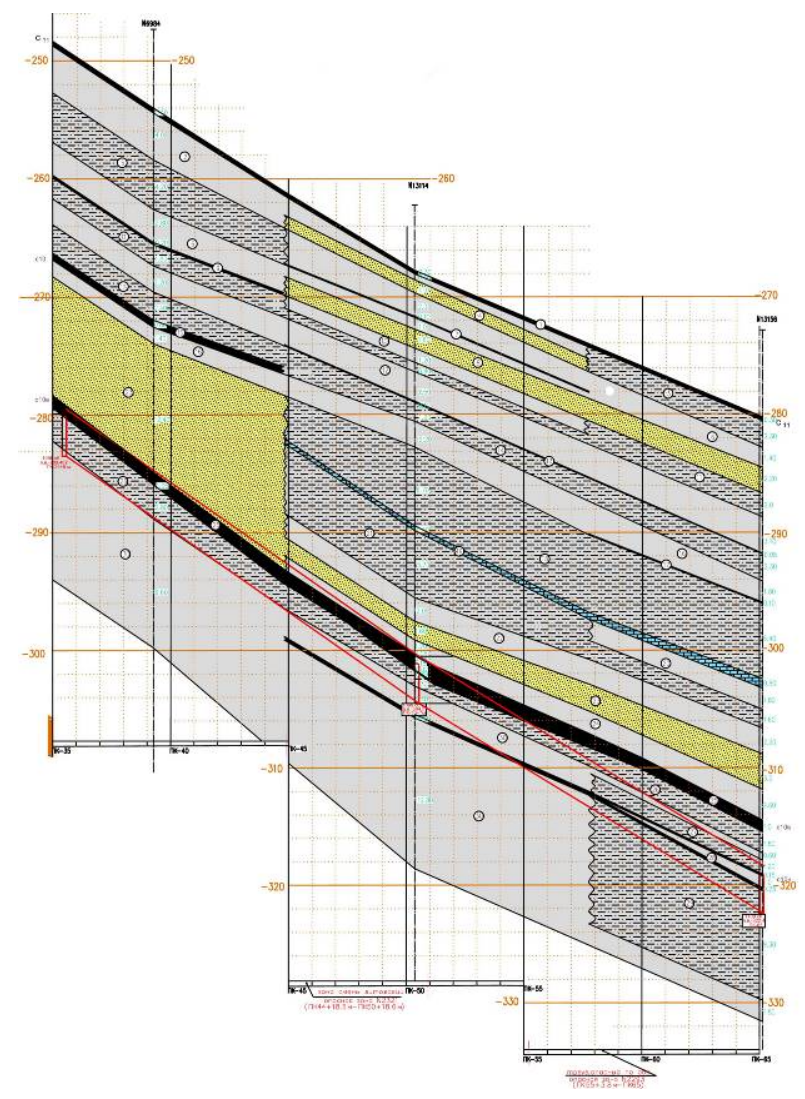

Fig. 2. Predictive geological sheet along the NDS of the seam $C_{10}{ }^{l} 265$ m horizon.

Weak resistance of the immediate roof plays an ambiguous role in the issues under study. From the point of view of the bearing pressure formation in the protecting pillar, the weak, easily deformable and weakened immediate roof functions as a damper, partially smoothing out the stresses concentrations in the area of the border with the mined-out space. On the other hand, it is possible to unambiguously predict argillite collapse throughout entire its thickness over the NDS arch, which forms a relatively small vertical and oblique load on the mine working support.

The adjacent two layers of the main roof are represented by sandstone with a thickness of $1.6 \mathrm{~m}$ and argillite with a thickness of $2.0 \mathrm{~m}$. The sandstone is water-flooded and loses its hardness from 20 to $40 \%$ [16] with its rather mean compressive resistance in the sample $\sigma_{\text {compr }}=11.7-53.3 \mathrm{MPa}$. Argillite is not hard $\left(\sigma_{\text {compr }}=7.7-26.4 \mathrm{MPa}\right)$, and with partial moistening of its lower part from the water-bearing sandstone, it can be considered a weak unstable lithotype. Moreover, the adhesive forces on the bedding surfaces are very low, and with horizontal shifts (for example, in the bearing pressure zone), the contacts are completely disturbed. Above siltstone occurs, divided by an interlayer of limestone (with a thickness of $0.4 \mathrm{~m}$ ) into two parts: lower - with a thickness of $5.7 \mathrm{~m}$ with $\sigma_{\text {compr }}=23.5-$ 29.7 $\mathrm{MPa}$; upper - with a thickness of $6.7 \mathrm{~m}$ with $\sigma_{\text {compr }}=12.0-34.1 \mathrm{MPa}$. With a relatively mean hardness and a predominantly naturally moist state of siltstone, its behaviour can be assessed as a quite stable due to the increased thickness.

The roof rocks composition is described to a height of $17.6 \mathrm{~m}$; the overlying lithotypes, according to the existing concepts $[10,11]$, will be deformed (during the stope works operations) without discontinuity, although it is likely that thick siltstone layers will be resistant even when partially divided into blocks due to formation of thick thrust-block systems. In the lower part of the main roof, weakened sandstone and argillite with a medium thickness will definitely collapse into the mined-out space, and the rock cantilevers, hanging from them, have a small length. Both above factors facilitate the formation (at the mined-out space boundary) of the bearing pressure zone with a low stresses concentration, which will decrease when moving backward into a virgin massif in the direction of the NDS of the seam $C_{10}$. Around the mine working itself, the weakened rocks border area formation is possible, since sandstone and argillite in the roof are not sufficiently stable.

The following lithotypes are located in the sides and the bottom of the NDS of the seam $C_{10}{ }^{l}$ : the coal seam itself is quite hard $\left(\sigma_{\text {compr }}=40.0-50.0 \mathrm{MPa}\right)$, but fractured and water-flooded with weakened contacts along the bedding planes; in the immediate bottom, siltstone with a thickness of $1.3-1.8 \mathrm{~m}$, most likely water-flooded with $\sigma_{\text {compr }}=15.6-24.1 \mathrm{MPa}$; in the main bottom, argillite occurs, divided by the coal seam $C_{10}{ }^{u}$ into two layers with $\sigma_{\text {compr }}=10.0-33.2 \mathrm{MPa}$. The indicated massif structure in the sides and the nearest layers of the mine working bottom suggests the development of an increased lateral bearing pressure onto the support, and the bottom water-cut provokes its intense heaving $[17,18]$. The so-called "stamp effect" should be added to this [19], when a harder coal seam presses-out (due to an increased vertical pressure) the less hard and easily deformable underlying rocks into the sides and the bottom of mine working.

Therefore, the following preliminary conclusions can be made at the first site of the dangerous zone:

- in a coal protecting pillar, in the area of the border with the mined-out space, the bearing pressure zone will be characterized by reduced stresses concentrations;

- a differently vectored rock pressure will be formed around the NDS of the seam $C_{10}{ }^{l}$ with different intensity of the border rocks displacements in the roof, sides and bottom of mine working; 
- development of an unstable state of argillite and sandstone to a height of up to $4.8 \mathrm{~m}$ is possible in the roof of the NDS of the seam $C_{10}$, but it can be dramatically restricted by applying the combined roofbolting systems [20-22], with which the vertical and oblique load in the arch will decrease to safe values;

- an increased lateral load on the prop stays of the frame support is predicted in the sides of mine working, and to maintain their stable shape, it is proposed to set the lateral roof-bolts with their tail joints connected with the prop stays of the frame by means of pliable (rope) binders [23];

- an intensive heaving is supposed in the bottom of the NDS of the seam $C_{10}{ }^{l}$, which is partially restricted by lateral resin-grouted roof bolts, and the main method to resist to heaving is the same - periodic bottom rocks ripping.

At the second site of the NDS length of the seam $C_{10}{ }^{l}$, similar rock pressure manifestations are predicted, but there are some peculiarities.

The first peculiarity is connected with a change in the lithology of the seam $C_{10}{ }^{l}$ roof rocks and the deviation of mine working into its bottom. Now, a layer of siltstone with a thickness of $1.5-1.8 \mathrm{~m}$ is located above the mine working arch, and beginning with PK61, an interlayer of argillite with a thickness of $0-0.6 \mathrm{~m}$ appears directly on the contour as a kind of friable roof by analogy with the stope faces. The average compressive resistance of siltstone in the sample is $19.9 \mathrm{MPa}$, argillite - 21.6 MPa. Both lithotypes are of medium-bedded stratification and their water saturation from the seam $C_{10}{ }^{l}$ is predicted. For this reason, an unstable state of border rocks should be expected in the NDS roof to the thickness height of siltstone and argillite. The coal seam $C_{10}{ }^{l}$, despite its relative hardness, is water-flooded and fractured; therefore, it can be classified as weakly stable. The argillite of the immediate roof of the seam $C_{10}{ }^{l}$ with a thickness of $2.0-2.6 \mathrm{~m}$ is water-flooded, hence, it is difficult to express an unequivocal opinion in terms of its stability. The first layer of the main roof is represented by sandstone with a thickness of $2.4-3.0 \mathrm{~m}$ with an average compressive resistance of $32.5 \mathrm{MPa}$, and despite its water-cut, the lithotype can be assessed as stable.

Thus, formation of a vast region of unstable rocks up to $6.0 \mathrm{~m}$ high over the NDS arch of the seam $C_{10}{ }^{l}$ is possible, which is able to form a vertical and oblique load of a dangerous value.

From the point of view of the protecting pillar state at the border with the mined-out space, an attention should be paid here to the change in the composition of the main roof rocks of the seam $C_{10}{ }^{l}$. There partial replacement occurs of siltstone with argillite and two lithotypes with medium thickness are formed $(1.6 \mathrm{~m}$ and $1.8 \mathrm{~m}$, respectively). Hard limestone is located above $\left(\sigma_{\text {compr }}=94.3-133.0 \mathrm{MPa}\right)$, but its low thickness (up to $0.8 \mathrm{~m}$ ) and fracturing indicate weak stability. The total thickness of the described lithotypes is up to $12.0 \mathrm{~m}$ and a variant of roof stratifications development to such a height is quite possible. The variant of the hinged-block displacement zone extension through the thickness $(6.4 \mathrm{~m})$ of the overlying siltstone up to a coal interlayer with a thickness of $0.1 \mathrm{~m}$ is less possible. Nevertheless, in both cases, the structure of the roof rocks of the seam $C_{10}{ }^{l}$ can be characterized as predominantly mediumbedded, with the rock cantilevers insignificantly overhanging into the mined-out space. Therefore, moderate stresses concentrations in the bearing pressure zone of the coal pillar should be predicted.

The second difference of the studied dangerous zone is a change in the rocks structure of the seam $C_{10}{ }^{l}$ bottom. Here, throughout the mine working height, mainly thin layers of argillite and siltstone are located, as well as coal seam $C_{10}{ }^{u}$ with a two-band structure. With a relatively insignificant hardness, all lithotypes are waterflooded, which, with a significant geostatic pressure $(H=420-450 \mathrm{~m})$, predicts the formation of large areas of weakened rocks in the NDS sides, as well as the development of a significant lateral load onto support.

The NDS bottom of the seam $C_{10}{ }^{l}$ is represented by a thick $(9.3 \mathrm{~m})$ siltstone with an average compressive resistance in the sample of $19.9 \mathrm{MPa}$. The siltstone stratification and a probability of water saturation of its upper bands suggest the development of heaving process from moderate to intense. However, in the mine working sides, there is no sufficiently rigid lithotype, and the existing thin and weakened lithological varieties are not able to create a "stamp effect". Therefore, it is expected that the predicted heaving will be of moderate value.

Summing up the analysis results of mining and geological situation as a whole around the NDS sites of the seam $C_{10}$, constructed according to the plan of mining operations, a preliminary assessment should be made:

- moderate stresses concentration in the bearing pressure zone along the protecting pillar width in the border area with the mined-out space is unlikely to influence the mine working state, and the possibility of reducing the protecting pillar width will be substantiated below when performing a computational experiment;

- it is predicted the development of differently vectored rock pressure manifestations on the mine working contour and it is recommended to use various engineering decisions to ensure its stability, in particular, combined roof-bolting systems and the structural coupling of lateral resin-grouted roof bolts with the prop stays of the frame support.

\section{Substantiation of the possibility to reduce the protecting pillar width}

A preliminary expert assessment of the coal-bearing massif state in the boundary area of the protecting pillar of the SDS of the seam $C_{10}{ }^{l}$ and the mined-out space, when the 1100 and 1001 longwall faces move backward from the face entry, indicates the low stresses concentration in the bearing pressure zone. The reason for this statement was revealed in the works [21, 22, 25]: easily deformable and relatively weak layers of the roof are not able to form any stretched rock cantilevers on the border of the mined-out space, which concentrate the bearing pressure near the protecting pillar border; low deformation characteristics of lithotypes (caused by discontinuity, stratification and water-cut), due to 
damping properties, localize the high rock pressure (HRP) areas at a limited coal pillar length; hence, the stope works influence in the 1100 and 1001 longwall faces does not extend in a protecting pillar to remote areas, including the area where the NDS of the seam $C_{10}{ }^{l}$ is located.

The above representations have been tested by means of a computational experiment using proven techniques $[18,23,26-28]$ as applied to the analysed mining and geological conditions. Taking into account the need to consider the complex of geomechanical and mining factors a conclusion about feasibility of modern computer programs by the FEM use is obvious for the solution of set problems: models creation - Solid Works program, the SSS calculation of the system elements in elastic approach - Desain Star application; materials anisotropy consideration - Cosmos- $M$ program, wide opportunities of Ansys complex. The computational experiment results are presented in the form of curves of vertical $\sigma_{\mathrm{y}}$, horizontal $\sigma_{\mathrm{z}}$ and intensity $\sigma$ stresses distribution along the protecting pillar width $z$, including the mined-out space to a length approximately twice the step of primary setting of the main roof.

Analysis of the vertical stresses $\sigma_{\mathrm{y}}$ curve (Figure 3) has revealed the following results.

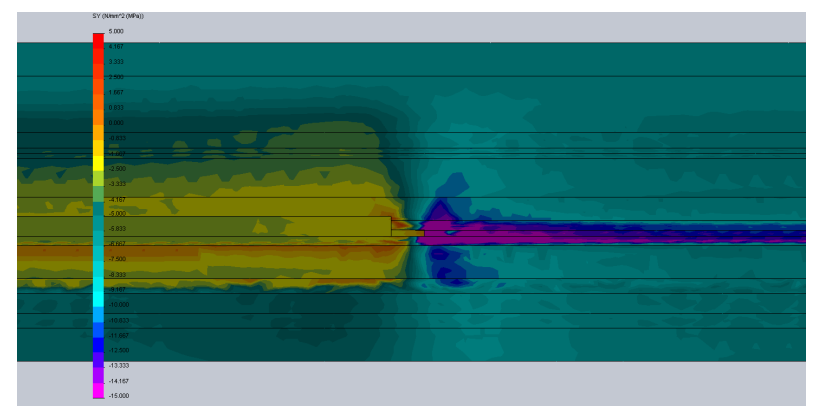

Fig. 3. The vertical stresses $\sigma_{\mathrm{y}}$ distribution across the protecting pillar width.

The dimensionless indicator $K_{\mathrm{y}}$ is the most informative parameter, which determines the effective value $\sigma_{\mathrm{y}}$ relative to geostatic vertical pressure $\gamma H$ of virgin massif (as denoted here: $H$ - depth of mining operations; $\gamma$-weight-average unit specific gravity of rocks in the coal-overlaying formation). The second indicator is the distance $l_{\mathrm{y}, \mathrm{z}}$ of a specific concentration value $K_{\mathrm{y}}$ distribution into the roof and bottom of the seam $C_{10}{ }^{l}$ (distance $l_{\mathrm{y}}$ ) and across the protecting pillar width (distance $l_{\mathrm{z}}$ ).

In full compliance with existing concepts, the highest concentrations of $K_{\mathrm{y}}$ were recorded near the protecting pillar border, adjacent to the mined-out space of the 1100 and 1001 longwall faces; the maximum distances $l_{\mathrm{y}, \mathrm{z}}$ of each discrete value propagation $K_{\mathrm{y}}$ are also noted here. Thus, the concentrations of $K_{\mathrm{y}} \geq 2.0-2.5$, capable of weakening the lithotypes of the coal-bearing stratum, develop into the seam $C_{10}$ roof to a height of up to $1.8 \mathrm{~m}$; into the bottom - to a depth of $1.6 \mathrm{~m}$; across the pillar width $l_{\mathrm{z}}-3.5-4.0 \mathrm{~m}$ and capture the immediate roof rocks, and in the coal seam itself, the local areas are observed at a distance of up to $3.0-3.5 \mathrm{~m}$; the greatest distance $l_{\mathrm{z}}$ to 5.0 is recorded in the immediate bottom rocks. The next category of vertical stresses concentration $K_{\mathrm{y}}=1.5-1.8$ is able to partially weaken the rocks of the immediate roof and bottom, taking into account their probable water saturation, but the harder lithotypes (coal seam $C_{10}$ l and sandstone of the main roof) retain their continuity and are capable of further resistive action to vertical rock pressure. The width of the partial weakening area is up to $8-9 \mathrm{~m}$ in the immediate roof, and up to $10-12 \mathrm{~m}$ in the immediate bottom.

The concentration level $K_{\mathrm{y}} \leq 1.5$ has the largest propagation area, in which the lithotypes of the adjacent coal-bearing stratum mainly retain their natural structure, and some local discontinuity is conditioned by water saturation, stratification and fracturing of the weakest rock layers - siltstone and argillite of the immediate bottom. As for the argillite of the immediate and main roof (occurring in the dangerous zone), the following situation is predicted here in the area of the protecting pillar with a width $l_{\mathrm{z}} \leq 8.0 \mathrm{~m}$.

It was previously noted that the immediate roof is definitely weakened, and the water-flooded sandstone remains continuity at $l_{\mathrm{z}} \geq 3.5-4.0 \mathrm{~m}$. But the second layer of the main roof, occurring above sandstone, is exposed to partial water saturation, and its separate samples (when tested for compression) have shown very low values of $\sigma_{\text {compr }}=7.7 \mathrm{MPa}$. Such compressive resistance, even with $K_{\mathrm{y}}<1.5$, presumes argillite weakening of the main roof second layer to a coal pillar width of up to $8.0 \mathrm{~m}$. Argillite with the same strength properties is the fourth layer of the main roof, located at a height of about $10 \mathrm{~m}$ from coal seam $C_{10}{ }^{l}$. At this height,

a concentration of $K_{\mathrm{y}}=1.5$ is localized and is not propagated further. However, it is necessary to take into account a sufficiently large (for the Western Donbas conditions) depth of $H=420-450 \mathrm{~m}$ of mining operations and here the geostatic pressure, even at low concentrations $K_{\mathrm{y}}=1.2-1.3$, can partially weaken the separate argillite bands with $\sigma_{\text {compr }}=7.7 \mathrm{MPa}$. Therefore, it is quite predictable a formation of the weakly stable rocks area (in the dangerous zone) to a height of $12-$ $13 \mathrm{~m}$, where a thin limestone layer occurs.

This conclusion refers only to a border area of the protecting pillar with a width of up to $4.0 \mathrm{~m}$, but in weak argillite layers of the main roof it can be propagated over a width $l_{\mathrm{z}}=10-13 \mathrm{~m}$. Further into massif, the vertical stresses concentrations dramatically decrease, which reflects the following parameters:

- at a distance $l_{\mathrm{z}}=30-32 \mathrm{~m}$, insignificant concentrations of $K_{\mathrm{y}}=1.2-1.3$ level completely disappear in the main roof and its state is determined by the geostatic pressure of virgin massif; that is, at such a distance, the stope works influence is absent;

- in the immediate roof and the first layer of the main roof, the increased concentrations of $K_{\mathrm{y}}=1.5-1.8$ level are propagated locally to a distance of $l_{\mathrm{z}}=22-27 \mathrm{~m}$ mainly due to the sandstone tensile strain;

- in the coal seam $C_{10}$, due to its increased rigidity, the concentrations of $K_{\mathrm{y}}=1.8-2.0$ are acting up to the level of $l_{\mathrm{z}}=18-22 \mathrm{~m}$; for the same reason, the stope works influence in the immediate bottom can be 
observed up to $l_{\mathrm{z}}=22-24 \mathrm{~m}$.

With further removal from the boundary of minedout space, its influence on the of vertical stresses $\sigma_{\mathrm{y}}$ distribution disappears - the protecting pillar itself and the coal-bearing stratum approach to the state of a virgin massif.

Thus, according to the factor of the component $\sigma_{\mathrm{y}}$ action, the absence of the stope works influence in the 1100 and 1001 longwall faces at a distance of more than $32 \mathrm{~m}$ from the face entries has been proved. Therefore, with a certain safety factor of the prediction, it is quite expedient to leave the coal pillar with a width of $40-45 \mathrm{~m}$ for the protection of the NDS of the seam $C_{10} l$.

This conclusion has been tested by means of analysing the curve of the horizontal stresses $\sigma_{\mathrm{z}}$ distribution across the protecting pillar width $z$ and the stresses intensity $\sigma$, confirming the conclusions on vertical stresses.

Given a similar influence according to the action factors of vertical stresses $\sigma_{\mathrm{y}}$, horizontal stresses $\sigma_{\mathrm{z}}$ and stresses intensity $\sigma$, it can be considered reasonable to make an engineering decision on the NDS protection of the seam $C_{10}{ }^{l}$ by a coal pillar with a width of $40-45 \mathrm{~m}$.

\section{Measures development on conducting and maintaining the NDS of the seam $C_{10}{ }^{\prime}$ in the zone of the 1100 and 1001 longwall faces influence}

The measures to conduct and maintain the NDS of the seam $C_{10}{ }^{l}$ have been developed on the basis of scientific research and practical experience of the mine workings exploitation in the mining and geological Western Donbas conditions $[3,4,19]$. Earlier, the possible rock pressure manifestations has been preliminary assessed and general recommendations for ensuring the stable state of the NDS of the seam $C_{10}{ }^{l}$ has been made.

In this chapter, the recommended engineering decisions have been substantiated, including application of the method of computational experiment.

In the previous studies, a system of evidence was given that there is no stope works influence in the 1100 and 1001 longwall faces with a protecting pillar width of $40-45 \mathrm{~m}$. Here, substantiation is continued of absence of the stope works influence, based on the implementation of the following algorithm of actions.

Firstly, the main negative factors were distinguished earlier that (according to preliminary expert assessment) can significantly influence on the SDS stability of the seam $C_{10}{ }^{l}$ in the area of the 1100 and 1001 longwall faces location:

- possible asymmetry of the load on the mine working fastening structure needs to be tested by determining the SSS of the maintenance scheme main elements;

- there is a probability of arising an extensive arch of ultimate equilibrium around the NDS, which is able to form a high vertical and oblique load from the side of the roof rocks; the SSS analysis is required here of the previously recommended fastening structure in terms of effectiveness of its resistive action to rock pressure;
- an increased lateral load development on the fastening structure is possible - to check this, it is necessary to study the SSS of the prop stays of the frame support: assess the probability of their plastic bending.

Secondly, the measures substantiation to maintain the NDS of the seam $C_{10}{ }^{l}$ is performed on the fastening structure model, which is called "experimental" for the following reasons:

- to resist to vertical and oblique rock pressure, the frame support of TSYS series is strengthened by a combined roof-bolting system according to the recommendations $[29,30]$ of the resin-grouted roof bolts and rope bolts arrangement;

- a central prop stay of the strengthening support is set in the frame arch to control the danger level of the vertical and oblique loads development; it performs the functions of a "detector", which assesses the degree of its loading, the sufficiency of the used fastening elements or the necessity to supplement them with other structures; in addition, according to arising bending deformations in the central prop stay of the strengthening support, the level of the vertical load asymmetry is determined, that is, indirectly, the degree of the stope works influence;

- more significantly, the influence degree of the stope works in the 1100 and 1001 longwall faces is assessed by the level of loading the second "detector" of the lateral prop stay of the strengthening support, erected from the side of the coal pillar;

- the third "detector" is the prop stays of the TSYS frame support - according to the parameters of the stresses components distribution in them, the danger degree of plastic bending is determined, which serves as an indirect indicator of the lateral load value; then, the question should be solved, whether it is necessary to set (or not to set) the lateral resin-grouted roof bolts and strengthen the frame prop stays with the help of pliable binders with the roof-bolt tail joints.

The described methodological technique in the technology of performing the computational experiment enables, in our opinion, to solve all the tasks set for substantiating the measures to maintain the NDS of the seam $C_{10}{ }^{l}$ in the zone of the 1100 and 1001 longwall faces influence.

The SSS study of each main fastening structure element is performed on the three most informative components: vertical stresses $\sigma_{\mathrm{y}}$, horizontal stresses $\sigma_{\mathrm{z}}$ and stresses intensity $\sigma$.

A sequential analysis of the peculiarities of each component distribution has revealed that the vertical stresses $\sigma_{\mathrm{y}}$ curve, presented in Figure 4.

The first significant peculiarity of the curve $\sigma_{\mathrm{y}}$ is observed in the cap board of the frame support and characterized by its quite significant underloading (compared with the estimated yield limit $\sigma_{\text {yield }}$ of the SCP steel), despite the action of stresses with different signs.

The revealed situation with a very low loading of the frame cap board can be explained by three reasons:

- low vertical and oblique load from the limited dimensions of the arch of ultimate equilibrium;

- high reaction of the central and lateral prop stays of the strengthening support, which unloads the frame cap 
board;

- efficient performance of the combined roof-bolting system to create an armoured and rock plate with high load-bearing capacity.

The second peculiarity of the curve $\sigma_{\mathrm{y}}$ is the combination of a significant loading of the frame prop stays with a relatively uniform distribution of $\sigma_{\mathrm{y}}$ in the SCP cross section.

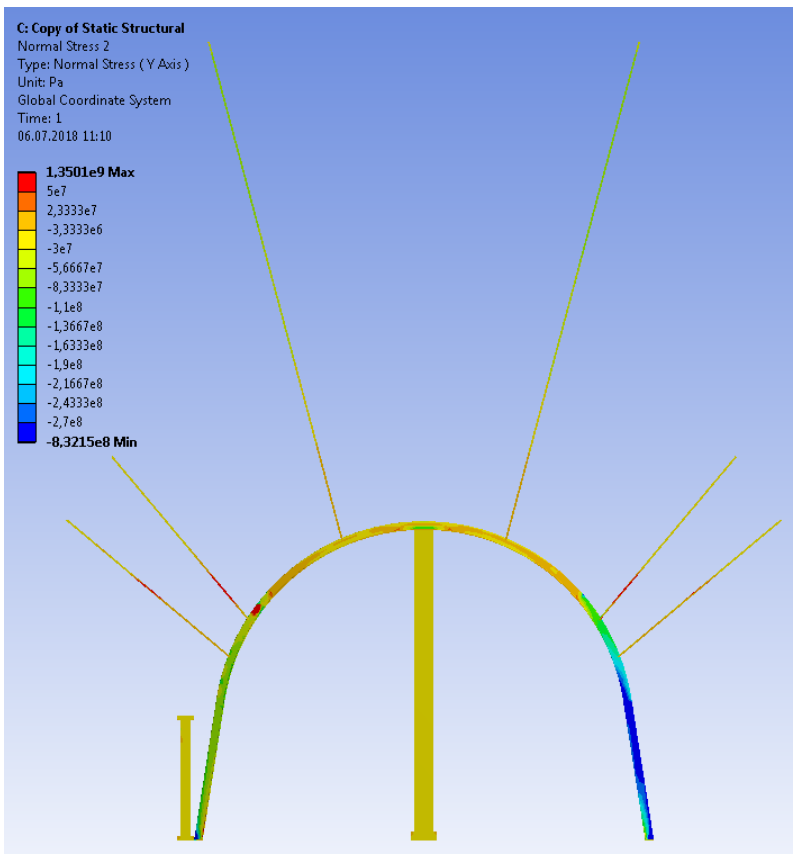

Fig. 4. Curve of vertical stresses $\sigma_{\mathrm{y}}$ in the preliminary variant of fastening structure of the NDS of the seam $C_{10} l$.

The above results make possible to draw the following conclusions. On the one hand, the frame prop stay experiences a significant vertical load, but within the permissible load-bearing capacity. This indicates the assumptions validity about the formation of an extensive arch of ultimate equilibrium. On the other hand, the frame prop stay copes with resistive action to lateral load, since there is practically no bending moment throughout its main height (about $80-85 \%$ ); only in the bearing area of the prop stay, a bending moment acts with a value that is not dangerous from the point of view of its plastic bending. The latter circumstance indicates the inexpediency of hardening the NDS sides with the roof-bolts and strengthening the frame prop stays with pliable binders.

Similar result $\sigma_{\mathrm{y}}$, in terms of quality, has also been obtained for the left frame prop stay, adjacent to the protecting pillar. Only here, the value of compressive stresses $\sigma_{\mathrm{y}}$ was $30-33 \%$ less than in the right frame prop stay, which is conditioned by the influence of the lateral wooden prop stay of the strengthening support.

From the third peculiarity of $\sigma_{\mathrm{y}}$ distribution, described above, the following conclusions can be drawn. Firstly, there are no bearing pressure effects in the protecting pillar (with a width of $40 \mathrm{~m}$ ) on the increase in vertical load in the adjacent prop stay of the frame. On the contrary, the total resistance reaction of the lateral wooden prop stay and frame prop stay is slightly reduced. Secondly, the lateral wooden prop stay is not only weakly loaded, but also does not experience any bending forces. This indicates the absence of increased rock pressure from the side of protecting pillar.

The fourth peculiarity of the curve $\sigma_{\mathrm{y}}$ relates to the central wooden prop stay of the strengthening support and reflects two facts: very low level of loading about $15-20 \%$ of the estimated load-bearing capacity value; practical absence of bending moment throughout the entire height. The first fact indicates that the frame support and the combined roof-bolting system quite cope with rock pressure: the central prop stay of the strengthening support is not necessary. The second fact notes the absence of any significant asymmetry in the fastening structure loading, and, consequently, the stope works influence through the protecting pillar.

Summing up the analysis results of the vertical stresses $\sigma_{\mathrm{y}}$ distribution in the fastening structure of the SDS of the seam $C_{10}{ }^{l}$, it is necessary to highlight the following basic provisions:

- the fastening structure as part of the frame support of the TSYS series and the combined roof-bolting system resists to rock pressure with some reserve of load-bearing capacity;

- with the protecting pillar width of $40 \mathrm{~m}$, the stope works influence in the 1100 and 1001 longwall faces is not revealed;

- the conclusions of the preliminary expert assessment were amended in terms of lack of the necessity to set resin-grouted roof bolts in the mine working sides and their connecting with the prop stays of the frame support.

The horizontal stresses distribution and the stresses intensity in the elements of the fastening structure supplement the earlier conclusions about its stability degree.

The almost complete absence of bending moment both in the prop stays of the frame (with the exception of an area of their bearings) and in the wooden prop stays of the strengthening support indicates the same absence of oblique load from the side of the coal pillar. It can be concluded from here that the width $40 \mathrm{~m}$ of the last excludes the stope works influence in the 1100 and 1001 longwall faces.

Assessing the degree of loading the roof bolts of the combined roof-bolting system, it should be noted that there is a reserve of load-bearing capacity of at least $30-35 \%$, which is included into the safety factor of the recommended fastening structure.

Summing up the performed research results, it can be considered that the evidence base has been created for the measures development on conducting and maintaining the NDS of the seam $C_{10}$ in the zone of the 1100 and 1001 longwall faces influence in "Dniprovska" Mine.

\section{Measures on conducting and maintaining the NDS of the seam $C_{10}{ }^{l}$}

To ensure a stable state of the North Drain Slope of the seam $C_{10}{ }^{l}$ for the entire period of its exploitation, the 
following measures have been developed:

1. In order to exclude the stope works influence in the 1100 and 1001 longwall faces, planned by the time schedule, to form from their side a protecting pillar with a width of at least $40-45 \mathrm{~m}$.

2. During the period of the new site development of the NDS of the seam $C_{10}{ }^{l}$, apply the fastening structure, including the frame support of the TSYS series and the combined roof-bolting system in accordance with the scheme in Figure 5.

3. The frame support is set with a step of $0.8 \mathrm{~m}$ with a tightening of the interframe space by means of a cyclone fencing.

4. The combined roof-bolting system includes $6.0 \mathrm{~m}$ long rope bolts, being set in a chessboard pattern (with respect to the mine working sides) with a step of $3.2 \mathrm{~m}$, as well as two pairs at a time resin-grouted roof bolts of $2.4 \mathrm{~m}$ long erected in the middle of the interframe space in each side with a step of $0.8 \mathrm{~m}$.

5. To be actively engaged in the work to resist to the border massif stratification, the combined roof-bolting system is erected with the minimum possible (for technological reasons) lagging behind the drifting face.

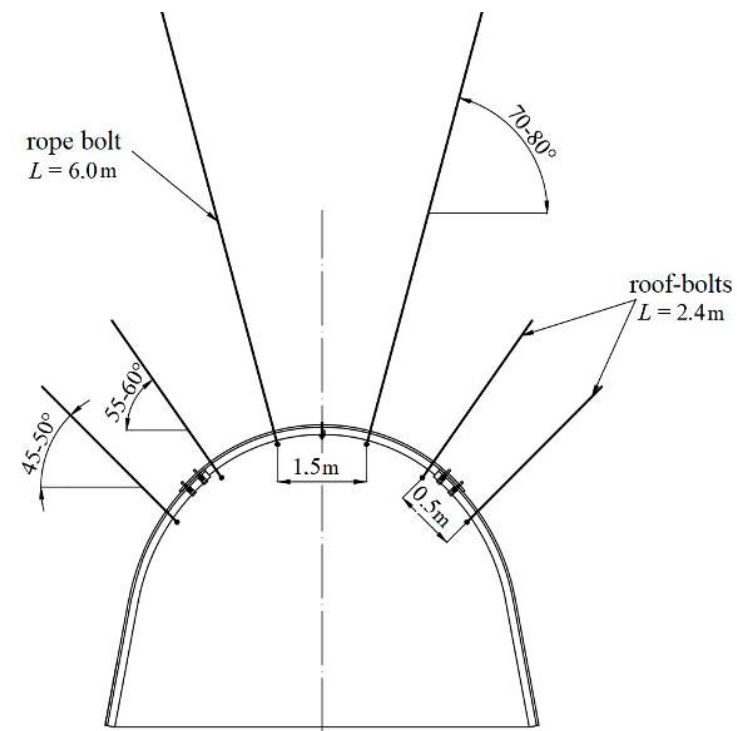

Fig. 5. Scheme for the fastening structure of the NDS of the seam $C_{10}$.

The experimental and industrial testing of frame-roof bolt support with self-regulated load redistribution, has shown its high efficiency in terms of mine working sides displacements restriction. The mine working is in stable condition along the whole its extent, and displacements of rock contour are considerably lower than vertical and side constructive support yield.

\section{Conclusions}

Summing up the performed research results, it can be concluded about the methodology development for optimizing the protecting pillars parameters. Using the example of "Dniprovska" Mine of DTEK "Pavlohradvuhillia" PRAT and, with the application of the method of computational experiment, the possibility of reducing the protecting pillar width has been proven. Based on the SSS analysis of the "massif - fastening system - protecting elements" system state, the measures have been developed on conducting and maintaining of mine workings in the zone of the stope works influence.

The authors express their gratitude to the management of DTEK Coal Unit for their help in organizing the experimental research.

\section{References}

1. M. Barabash, Material of Sch. of Und. Min., 1-2 (2017)

2. Energetika: istoriia, nastoiashchee i budushchee (2013), http://energetika.in.ua/ru/books/book-1/part2/section-7/7-7. Accessed 21 Mar 2020

3. V. Bondarenko, I. Kovalevs'ka, V. Fomychov, Geomechanical Processes during Underground Mining, in School of Underground Mining (2012), pp. 7-13

4. A. Bulat, B. Blyuss, A. Dreus, B. Liu, S. Dziuba, Min. of Miner. Dep. 13, 1 (2019)

5. V. Buzylo, V. Yavorskyi, A. Yavorskyi, S. Yunak, in Materials of Sch. of Und. Min. (2017), pp. 47-48

6. I. Kovalevska, M. Zhuravkov, V. Chervatiuk, O. Husiev, V. Snihur, Min. of Miner. Dep. 13, 3 (2019)

7. V. Lozynskyi, P. Saik, M. Petlovanyi, K. Sai, Z. Malanchuk, Intern. J. of Eng. Res. in Africa, 35 (2018)

8. V. Bondarenko, H. Symanovych, J. Kicki, M. Barabash, I. Salieiev, Min. of Miner. Dep. 13, 2 (2019)

9. S. Skipochka, O. Krukovskyi, S. Serhiienko, I. Krasovskyi, Min. of Miner. Dep. 13, 1 (2019)

10. M.P. Zborshchik, V.V. Nazimko, Protection of the workings of deep mines in the de-stressed zone (Tekhnika, Kyiv, 1991)

11. A.V. Savost'yanov, V.G. Klochkov, Managment of the rock massif state (UMK, 1992)

12. Yu.M. Khalimendik, A.V. Bruy, Ed. vol. of Don. St. Tech. Univ. 20, 35-43 (2005)

13. T. Majcherczyk, Z. Niedbalski, P. Malkowski, Int. Min. Forum, 37-46 (2007)

14. D. Babets, O. Sdvyzhkova, O. Shashenko, K. Kravchenko, E.C. Cabana, Min. of Miner. Dep. 13, 4 (2019)

15. V. Tymoshchuk, Ye. Sherstiuk, Z. Niedbalski, T. Morozova, Min. of Miner. Dep. 11, 2 (2017)

16. SOU 10.1.00185790.011:2007, Development workings on flat seams. Support selection, ways and means protection (Standart, DonVUGI, 2008)

17. P. Małkowski, Ł. Ostrowski, J. Brodny, J. of Sus. Min. 17, 3 (2018)

18. W. Masny, S. Prusek, G. Mutke, Proc. Eng. 191 (2017) 
19. N. S. Bulychev, The mechanics of underground building (Nedra, Moscow, 1982)

20. M. Madziarz, Min. Sc. 22 (2015)

21. Yu. Weijian, Wu. Genshui Wu, Min. Sc. 24 (2017)

22. A. Walentek, T. Janoszek, S. Prusek, A. Wrana, Int. J. of Min. Sc. and Tech. 29, 4 (2019)

23. S. Prusek, S. Rajwa, A. Wrana, A. Krzemień, Int. J of Min., Recl. and Env., 31, 8, (2017)

24. Z. Niedbalski, P. Małkowski, T. Majcherczyk, Tunnelling and Underground Space Technology 74, 41-59 (2018). doi:10.1016/j.tust.2018.01.003

25. R. Timchenko, S. Popov, M. Stupnik, D. Krishko, GEOMATE 9, 1 (2015)

26. S. Bock, S. Prusek, Comp. and Geot. 66 (2015)

27. M. Stupnik, V. Kalinichenko, O. Kalinichenko, I. Muzyka, M. Fed'ko, S. Pys'menniy, Metal. and Min. Ind. 7 (2015)

28. V. Golik, Y. Razorenov, V. Morkun, N. Morkun, E3S Web of Conf. 60 (2018)

29. M. Toderas, Multid. Sc. GeoConf. Surv. Geol. and Min. Ecol. Manag. 3, 1, 521-528 (2014)

30. P. Janas, K. Janas, L. Koubova, M. Krejsa, Key Eng. Mater. 754, 313-316 (2017). doi:10.4028/www.scientific.net/KEM.754.313 